\title{
Dynamic Performance Analysis for Different Vector-Controlled CSI- Fed Induction Motor Drives
}

\author{
Arul Prasanna Mark ${ }^{\dagger}$, Gerald Christopher Raj Irudayaraj*, Rajasekaran Vairamani*, \\ and Kaliamoorthy Mylsamy*
}

$\dagger^{* *}$ Dept. of Electrical and Electronics Engineering, PSNA College of Engineering \& Technology, Dindigul, India

\begin{abstract}
High-performance Current Source Inverter (CSI)- fed, variable speed alternating current drives are prepared for various industrial applications. CSI-fed Induction Motor (IM) drives are managed by using different control methods. Noteworthy methods include scalar Control (V/f), Input- Output Linearization (IOL) control, Field- Oriented Control (FOC), and Direct Torque Control (DTC). The objective of this work is to compare the dynamic performance of the aforementioned drive control methods for CSI-fed IM drives. The dynamic performance results of the proposed drives are individually analyzed through sensitivity tests. The tests selected for the comparison are step changes in the reference speed and torque of the motor drive. The operation and performance of different vector control methods are verified through simulations with MATLAB/Simulink and experimental results.
\end{abstract}

Key words: AC drives, CSI, DTC, FOC, Induction Motor, IOL, Vector control

\section{INTRODUCTION}

Three-phase squirrel-cage induction motors (IMs) are widely used as industrial drives because they are rugged, highly reliable, and economical. Single-phase IMs are extensively used for light loads on home appliances such as fans and, small water pumps. Although these IMs are traditionally used for fixed-speed applications, they are currently being increasingly used with variable-frequency drives (VFDs) in variable-speed applications. VFDs provide important energy-saving opportunities to existing and prospective IMs in variable-torque centrifugal fans, pumps, and compressor load applications. Squirrel cage IMs are widely used in both fixed-speed and VFD applications. Direct current (DC) motors, particularly separately excited types, were widely used in the past because of their easy speed and torque controllability. An IM has a rugged structure because it is brushless and has few internal parts that should be maintained or replaced. These characteristics makes IMs cheaper compared with other motors, such as DC motors. Pulse-width modulation (PWM) with a voltage source inverter (VSI) is typically used in variable-speed electric motor applications with low to moderate power. However, the

Manuscript received Apr. 11, 2014; accepted Jul. 10, 2014

Recommended for publication by Associate Editor Dong-Hee Lee.

†Corresponding Author: arulprasanna@psnacet.edu.in

Tel: +919944752376, PSNA College of Engineering and Technology

* Dept. of Electrical and Electronics Engineering, PSNA College of Engineering and Technology, India switched voltages produce high voltage slopes over stator windings, which stress insulations and cause bearing current problems. A possible solution is to use PWM with a current source inverter (CSI). Phillips [1], Lipo [2], Palaniappan [3], Jung [4], Krishnan [5], Kazmierkowski [6], and Kim [7] attempted to develop CSI to make it suitable for AC motors (particularly IMs) with variable speed drives. Both stator current and voltage waveforms are close to the sinusoidal waveform; this condition reduces the occurrence of the aforementioned problems. A CSI can also be used for high-power applications. High-performance CSI-fed variable speed drives, particularly IM drives, have been managed by using different control methods in recent years. Important methods include vector-based scalar control $(V / f)$, input-output linearization (IOL) control, Indirect Field Oriented Control (IFOC), and Direct Torque Control (DTC). Each method has its own unique features. The four methods are analyzed dynamically under steady and simulated states by using MATLAB/Simulink in this paper. The main objective of this paper is to ascertain different vector control methods for CSI-fed IM drives, which is similar to the work of Holmes [8], and to apply dynamic parameters to these methods. This paper also discusses the dynamic responses of each drive against step changes in speed and simultaneous torque references. These factors can help improve understanding on drive behavior for sudden changes in torque and speed for the four vector control techniques.

This paper focuses on the control and dynamics of CSI-fed 


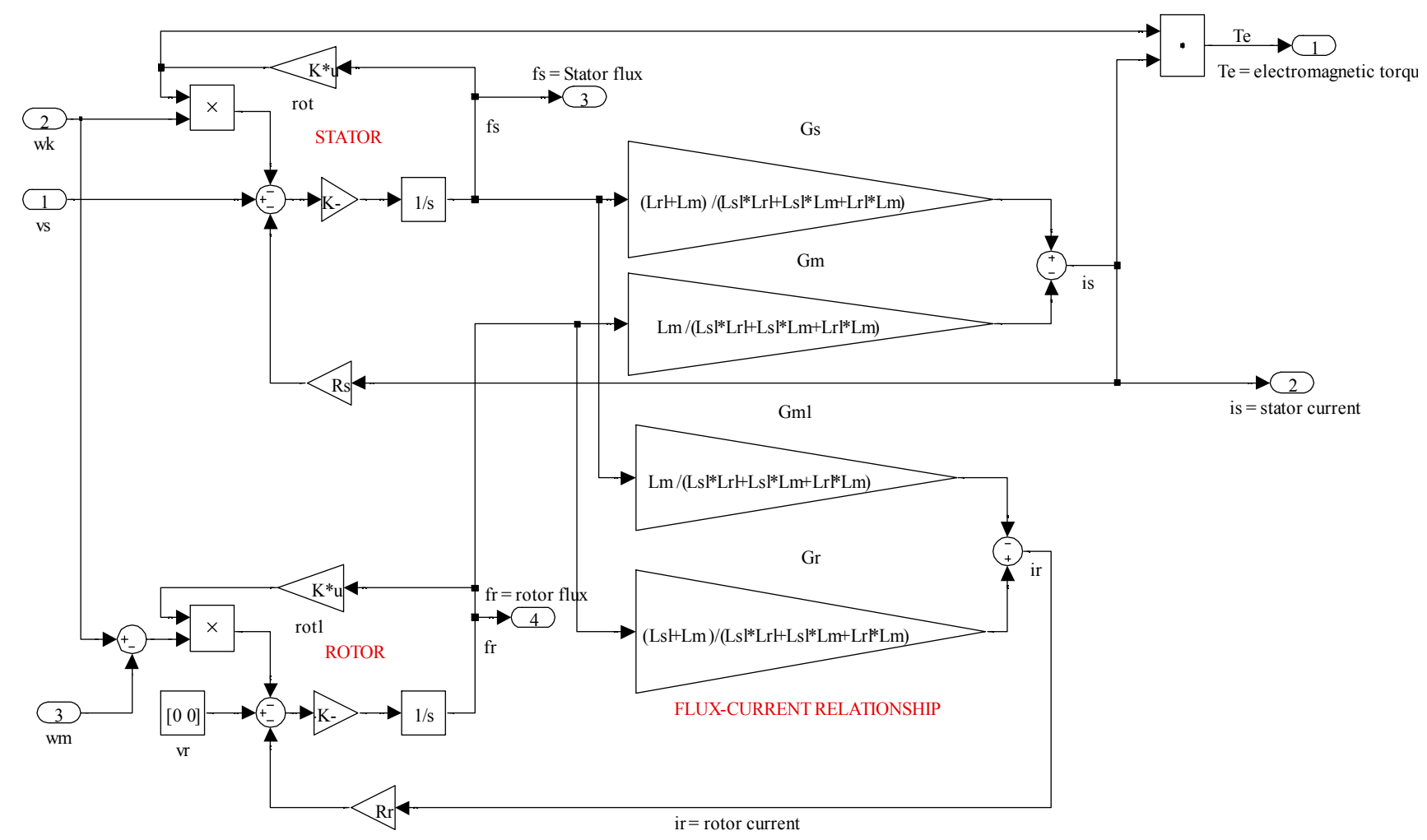

Fig. 1. IM modeling in an arbitrary reference frame.

IM drives and compares the steady-state and dynamic performances of the four control methods for CSI-fed IM drives by applying MATLAB simulation procedures. To date, most simulation works for this type of drive system have been performed under a steady state. Using general-purpose simulation programs such as Electromagnetic Transient Program and Simulation Program with Integrated Circuit Emphasis to simulate the dynamic performance of the drive system is difficult because of the special PWM techniques that Ledwich [9] employed in the inverter and the complicated IM model. Thus, specially designed computer simulation programs are required. Simple simulation algorithms have been developed for the four control techniques, and drive behavior is analyzed through simulation and experimental results. From the results, a comparative analysis is performed on the four control techniques to determine the best control methodology for dynamic load-changing drives used in industries.

\section{MATHEMATICAL MODELING OF IM}

The IM modeling is shown in Fig.1. In general, IM is used to transform electrical energy into mechanical energy. It consists of an electric, electromagnetic, and electromechanic circuitries Krishnan[10]. The main objective of the motor modeling is to build a simple but competent model that describes the aforementioned circuits and their interconnections. The main path in the model is related to voltage and current or the stator phases in the input, whereas the magnetic flux within the motor and electromagnetic torque are related to the output.

The squirrel cage IM is prepared for industrial applications. This IM can be supplied either by a voltage source or a current source. These sources are assumed to be ideal, which indicates that they can supply any desired voltage or current without losses. Krause [11] reported that basic IM equations are those of the stator voltage [Equation (1)], rotor voltage [Equation (2)], flux linkages of the stator and rotor winding systems [Equations (3) and (4), respectively], and torque [Equation (5)], which are as follows:

$$
\begin{gathered}
V_{s}^{s}=R_{s} i_{s}^{s}+\lambda_{s}^{s}, \\
V_{r}^{r}=0=R_{r} i_{r}^{r}+\lambda_{r}^{r}, \\
\lambda_{s}^{2}=\lambda_{m}^{2}+L_{i s} i_{s}^{2}, \\
\lambda_{r}^{2}=\lambda_{m}^{2}+L_{i r} i_{r}^{2}, \\
T_{e}=\left[C\left(\frac{\pi}{2}\right) \lambda_{m}^{2}\right]^{2} i_{s}^{2} .
\end{gathered}
$$

The equations are provided in vector format by Bose [12]. Each vector variable has two components. The first component is parallel to the reference frame axis or $d$ axis, whereas the second component is perpendicular to the reference axis or $q$ axis. The symbols are as follows: $v$ is the voltage, $I$ is the 
(a) Stator Rotating Reference Frame

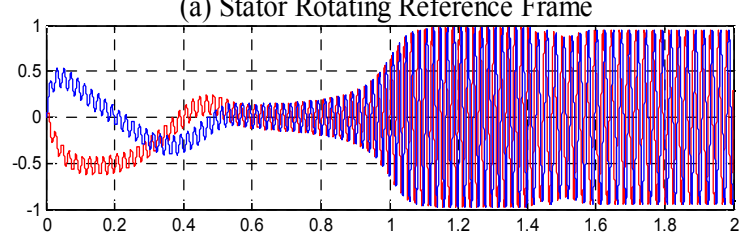

(b) Rotor Rotating Reference Frame

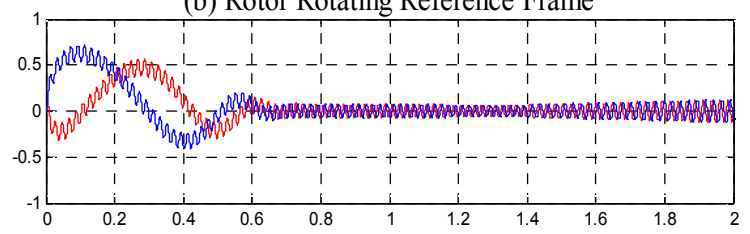

(c) Synchronous Rotating Reference Frame

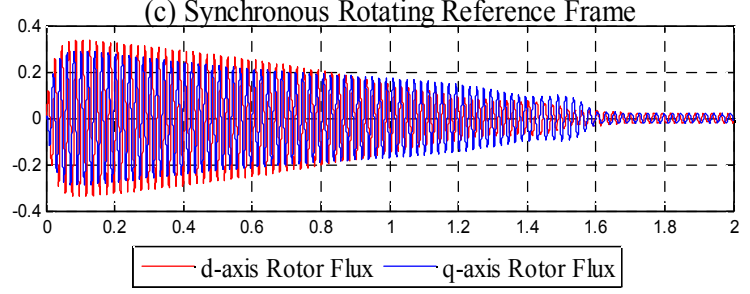

Fig. 2. Rotor flux linkage in the $d-q$ axis.

current, $\lambda$ is the flux linkage, $R$ is the resistance, and $L_{i}$ is the leakage inductance. The subscripts $s$ and $r$ indicate the stator and rotor winding systems, respectively. The superscripts $s$ indicates the stator reference frame (stator coordinates), $r$ is the rotor reference frame, and $a$ is any arbitrary reference frame. $\lambda_{m}$ is the magnetic flux in the motor air gap or the air gap flux, $T_{e}$ is the electromagnetic torque, $\mathrm{C}(\pi / 2)$ is a rotation matrix over $\pi / 2$ radians, and the dot () indicates a time derivative. Equation (1) is restricted to the stator reference frame because of the differential of the stator flux vector. Equation (2) is restricted to the rotor reference frame because of the differentiation. The flux and torque equations can be defined in any reference frame and denoted by the superscript $a$.

Equations (1) to (5) show that the motor voltage, flux, and torque can be managed easily by controlling the current and flux of the motor.

The rotor flux linkage waveform in the $d-q$ axis is shown in Fig. 2 for all three reference frames, namely, the stator, rotor, and synchronous rotating reference frames. A steady-state operation is achieved quickly in the rotor rotating reference frame unlike in the other two control frames. This frame type is used to control the dynamic response of the motor parameters, particularly in the DTC technique for efficient torque control applications.

\section{III. $V / F$ CONTROL FOR CSI-FED IM DRIVES}

This section presents a simplified computer program for the simulation of a CSI-fed IM drive control via vector-based $V / f$ control method by using MATLAB/Simulink simulation software. The main features of this type of simulation program

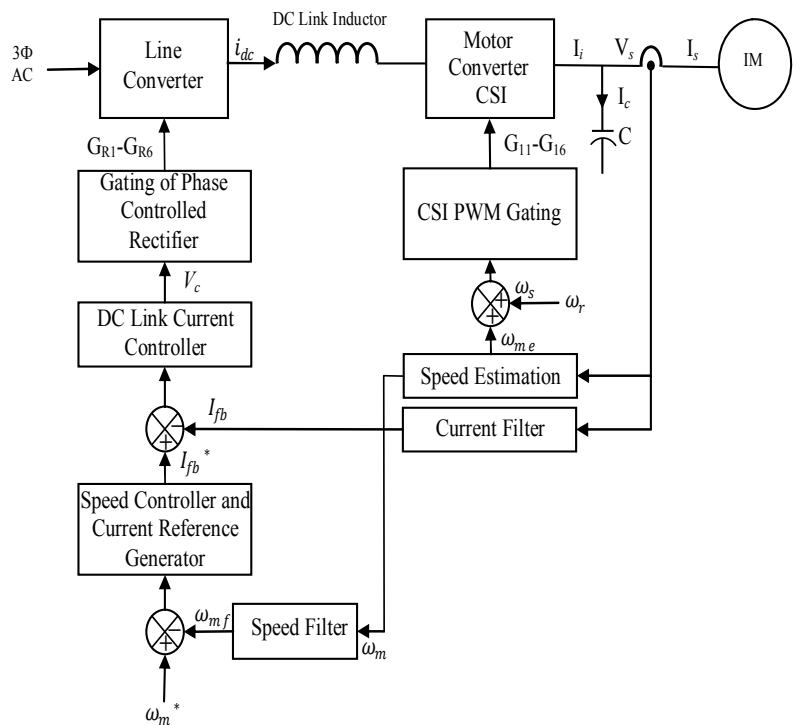

Fig. 3. Control block diagram of the CSI-fed IM drive system.

are its simplicity, accuracy, and efficiency in terms of computation time. This simulation program can be used to verify system design, study system dynamic behavior, and investigate steady-state waveforms of the drive system. The feasibility and reliability of the system, as well as the validity of the control method, are proven by the simulation results. The CSI drive shown in Fig. 3 has many features compared with VSI drives. When used as a switching device in the CSI, a symmetrical gate turn-off thyristor also makes the drive particularly suitable for implementation at medium- and high-voltage levels. The corresponding state equation (differential equation) with motor flux linkages as variables is derived from the work of $\mathrm{Wu}$ [13].

$$
x=A x+B u,
$$

where $\dot{x}=\frac{d x}{d t}$,

$$
\begin{aligned}
& A=\left[\begin{array}{cccccccc}
-\frac{R_{s}}{\sigma_{m} L_{m}} & 0 & \frac{R_{s}}{L_{l}} & 0 & 1 & 0 & 0 & 0 \\
0 & -\frac{R_{s}}{\sigma_{m} L_{m}} & 0 & \frac{R_{s}}{L_{l}} & 0 & 1 & 0 & 0 \\
\frac{R_{r}}{L_{l}} & 0 & -\frac{R_{r}}{L_{l}} & -\omega_{m s} & 0 & 0 & 0 & 0 \\
0 & \frac{R_{r}}{L_{l}} & -\omega_{m s} & -\frac{R_{r}}{L_{l}} & 0 & 0 & 0 & 0 \\
-\frac{1}{\sigma_{m} L_{m} C} & 0 & \frac{1}{L_{1} C} & 0 & 0 & 0 & K(1) & 0 \\
0 & -\frac{1}{\sigma_{m} L_{m} C} & 0 & \frac{1}{L_{1} C} & 0 & 0 & K(2) & 0 \\
0 & 0 & 0 & 0 & K(3) & K(4) & -\frac{R_{d c}}{L_{d c}} & 0 \\
K_{t e} \lambda_{d r} & -K_{t e} \lambda_{d r} & 0 & 0 & 0 & 0 & 0 & 0
\end{array}\right] \\
& x=\left[\begin{array}{llllllll}
\lambda_{q s} & \lambda_{d s} & \lambda_{q r} & \lambda_{d r} & v_{q s} & v_{d s} & i_{d c} & \omega_{m e}
\end{array}\right]^{T} \\
& B=\left[\begin{array}{cccccccc}
0 & 0 & 0 & 0 & 0 & 0 & \frac{1}{L_{d c}} & 0 \\
0 & 0 & 0 & 0 & 0 & 0 & 0 & -\frac{P}{2 l}
\end{array}\right]
\end{aligned}
$$




$$
u=\left[\begin{array}{ll}
V_{d c} & T_{l}
\end{array}\right]^{t}
$$

This state equation is arranged such that it is valid for all states. Only the switching coefficients $K(1)$ to $K(4)$ in the equation need to be modified for different states. Therefore, simulation complexity is substantially reduced. This state equation is also expressed in the stator reference frame, and thus, time domain waveforms can be directly obtained by applying any numerical integration method without further transformation. A CSI is similar to a VSI except with a high-value DC-link inductor to ensure a constant current source. The operation of the inverter can be divided into six distinct states. Each state corresponds to a unique pair of on-state thyristors $\left(T_{1} T_{2}, T_{3} T_{4}\right.$, and $\left.T_{5} T_{6}\right)$. Reverse blocking diodes are also needed in CSI to prevent capacitors from discharging into the load. The numbering scheme for the thyristors and diodes for a three-phase CSI is shown in Fig. 4.

The CSI switching state is provided in Table I.

\section{IOL CONTROL FOR CSI-FED IM DRIVES}

A type of IOL control method for the CSI-fed IM drive is shown in Fig. 5. The controller is designed based on the pole placement technique of Wonham [14] to a $d-q$ axis state-space linearized model of the drive that includes a reduced order rotor current observer. A control law is developed to improve the dynamic response of the drive by applying the concepts of Veerachary [15]. These concepts include feedforward and feedback controls, as well as the linearized CSI-IM drive state-space model in a synchronously rotating reference frame as follows:

$$
\begin{gathered}
x=A x+B u \\
y=C x
\end{gathered}
$$

Tracking error possibly occurs under steady state when the usual state feedback control is used. Smith [16] introduced an integral control that includes feedback and feedforward controls to eliminate this error. An optimal control law is derived in this paper by applying the concepts of Smith [16]. A feedforward control in terms of reference and disturbance inputs is added to the feedback controller-observer to obtain a fast dynamic response either from Equations (9) or (10) as follows:

$$
u=K_{1} x+K_{2} \int_{0}^{t}\left(y-y_{r}\right) d t+K_{F F}\left[\begin{array}{l}
d \\
y_{r}
\end{array}\right]
$$

or

$$
u=K_{1(2 \times 4)}\left[\begin{array}{c}
\Delta i_{q s} \\
\Delta i_{q r} \\
\Delta i_{d r} \\
\frac{\Delta \omega_{r}}{\omega_{b}}
\end{array}\right]+K_{2(2 \times 2)}\left[\begin{array}{c}
\int_{0}^{t}\left(i_{q s}-i_{q s}{ }^{*}\right) d t \\
\int_{0}^{t}\left(\omega-i_{q s}{ }^{*}\right) d t
\end{array}\right]
$$

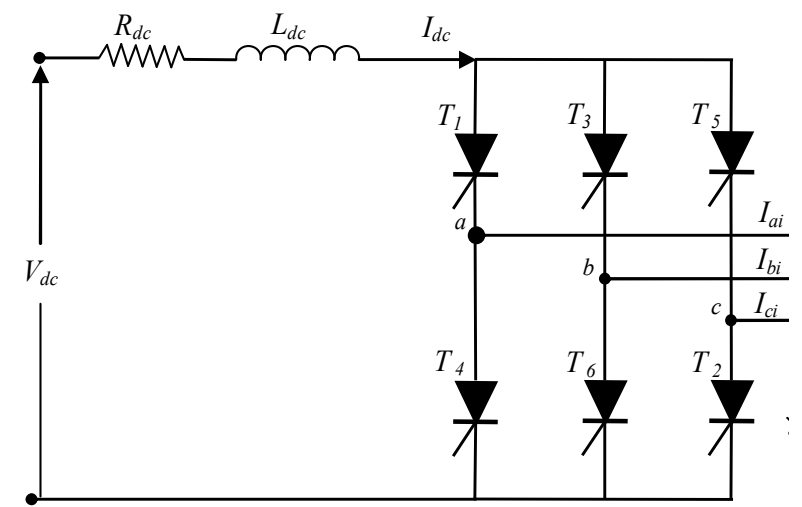

Fig. 4. Inverter circuit topology of the CSI-fed IM drive system.

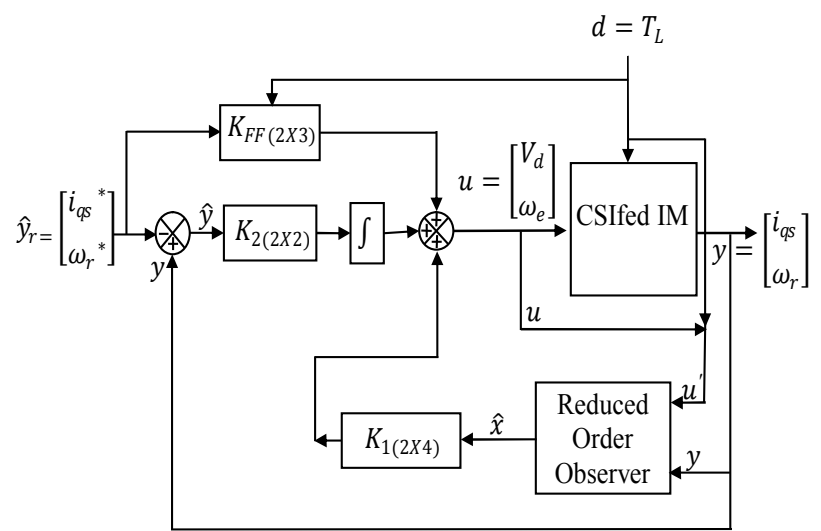

Fig. 5. Combined feedforward and integral feedback controller.

TABLE I

SWITCHING STATES

\begin{tabular}{cc}
\hline State & On-state thyristors \\
\hline 1 & $T_{1}$ and $T_{2}$ \\
2 & $T_{2}$ and $T_{3}$ \\
3 & $T_{3}$ and $T_{4}$ \\
4 & $T_{4}$ and $T_{5}$ \\
5 & $T_{5}$ and $T_{6}$ \\
6 & $T_{6}$ and $T_{1}$ \\
\hline
\end{tabular}

\section{IFOC FOR CSI-FED IM DRIVES}

This section describes a high-performance, current-fed indirect rotor flux-oriented (RFO) control method for IMs. The IM modeled in the rotor flux reference frame is presented. The rotor flux orientation is also obtained. The rotor flux components in the low-speed region can be synthesized easily with the help of speed and current signals. The design of the indirect vector controller and rotor flux estimator is discussed. IFOC implementation on the CSI-fed IM drive and transient response analysis of the other simulation results are also discussed. The rotor equations of the IM that contains flux linkages as variables are provided by Krause [17] as follows: 


$$
\begin{aligned}
& R_{r} i_{d r}^{e}+\rho \lambda_{d r}^{e}-\left(\omega_{e}-\omega_{r}\right) \lambda_{q r}^{e}=0 \\
& R_{r} i_{q r}^{e}+\rho \lambda_{q r}^{e}-\left(\omega_{e}-\omega_{r}\right) \lambda_{d r}^{e}=0
\end{aligned}
$$

where

$\omega_{s l}=\omega_{e}-\omega_{r}$

Then, Equation (11) becomes the following:

$$
\begin{aligned}
& R_{r} i_{d r}^{e}+\rho \lambda_{d r}^{e}-\omega_{s l} \lambda_{q r}^{e}=0 \\
& R_{r} i_{q r}^{e}+\rho \lambda_{q r}^{e}-\omega_{s l} \lambda_{d r}^{e}=0
\end{aligned}
$$

The resultant rotor flux linkage $\lambda_{\mathrm{r}}$, also known as the rotor flux linkage phasor, is assumed to be on the direct axis to reduce the number of variables in the equations by one. Rotor flux linkages are realistically a single variable. Thus, aligning the $d$ axis with the rotor flux phasor yields the following:

$$
\begin{gathered}
\lambda_{r}=\lambda_{d r}^{e} \\
\lambda_{q r}^{e}=0 \\
\rho \lambda_{q r}^{e}=0
\end{gathered}
$$

Substituting Equations (13) to (15) into Equation (12) results in the following new rotor equations:

$$
\begin{gathered}
R_{r} i_{d r}^{e}+\rho \lambda_{r}=0 \\
R_{r} i_{q r}^{e}+\omega_{s l} \lambda_{r}=0
\end{gathered}
$$

The rotor currents with respect to the stator currents are derived from Equation (16) as follows:

$$
\begin{gathered}
i_{q r}^{e}=-\frac{L_{m}}{L_{r}} i_{q s}^{e} \\
i_{d r}^{e}=-\frac{\lambda_{r}}{L_{r}}-\frac{L_{m}}{L_{r}} i_{d s}^{e} \\
i_{d s}^{e}=i_{f}=\left[1+\frac{L_{r}}{R_{r}} \rho\right] \frac{\lambda_{r}}{L_{m}} \\
i_{d s}^{e}=i_{f}=\left[1+\tau_{r} \rho\right] \frac{\lambda_{r}}{L_{m}} \\
\omega_{s l}=\frac{R_{r} L_{m}}{L_{r}} \frac{i_{q s}^{e}}{\lambda_{r}} \\
\omega_{s l}=\frac{R_{r} L_{m}}{L_{r}} \frac{i_{T}}{\lambda_{r}} \\
\omega_{s l}=\frac{L_{m}}{\tau_{r}} \frac{i_{T}}{\lambda_{r}}
\end{gathered}
$$

The currents of the $q$ and $d$ axes are relabeled as the torque$\left(i_{T}\right)$ and flux-producing $\left(i_{f}\right)$ components of the stator-current phasor, respectively. $\tau_{r}$ denotes the rotor time constant. Similarly, the electromagnetic torque is derived by substituting the rotor currents from Equation (17) into the torque expression as follows:

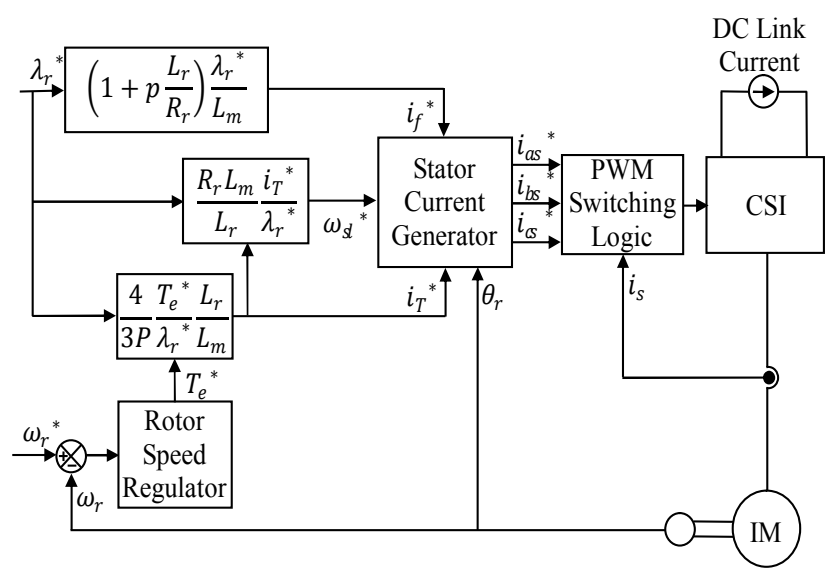

Fig. 6. Simulink diagram of the IFO control method.

$$
\begin{gathered}
T_{e}=\frac{3}{2} \frac{p}{2} \frac{L_{m}}{L_{r}}\left(\lambda_{d r}^{e} i_{q s}^{e}-\lambda_{q r}^{e} i_{d s}^{e}\right) \\
T_{e}=\frac{3}{2} \frac{p}{2} \frac{L_{m}}{L_{r}}\left(\lambda_{d r}^{e} i_{q s}^{e}\right) \\
T_{e}=K_{t e} \lambda_{r} i_{q s}^{e}=K_{t e} \lambda_{r} i_{T}
\end{gathered}
$$

where torque constant $K_{t e}$ is defined as follows:

$$
K_{t e}=\frac{3}{2} \frac{p}{2} \frac{L_{m}}{L_{r}}
$$

The torque is proportional to the product of the rotor flux linkage and the stator $q$-axis current. This condition resembles the air gap torque expression of the DC motor that is proportional to the product of the field flux linkages and the armature current. If the rotor flux linkage is maintained as a constant, then the torque is proportional to the torque-producing component of the stator current. This scenario is related to the separately excited DC motor with armature current control, wherein torque is proportional to the armature current when the field current is constant. The time constant is also measured in the order of a few milliseconds. The rotor flux linkages and air gap torque given in Equations (19) and (20), respectively, complete the transformation of the IM into an equivalent separately excited DC motor from a control perspective. The IFO controller is designed by applying the concepts of Vas [18] and Salo [19]. The relevant steps involved in the realization of the IFO controller are discussed briefly in literature.

The implementation of IFOC on a CSI-fed IM is shown in Figs. 6 and 7. The digital implementation of integrators for estimating the rotor flux of an IM from the stator voltages and stator currents poses problems associated with the offset in sensor amplifiers. Traditional low-pass filters can replace the integrator. Thus, the rotor flux estimated by using a low-pass filter is described in this work. The instantaneous flux linkage can be computed by using the measured $d$-axis stator current 


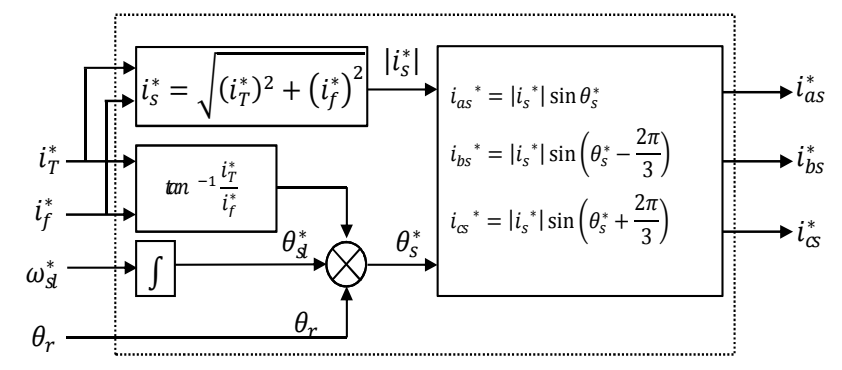

Fig. 7. Stator current generator.

according to the following equation, which is referred to as the current model:

$$
\lambda_{r}=\frac{L_{m} i_{d s}}{1+\tau_{r} s}
$$

\section{DTC-FED CSI IM DRIVE}

Variable speed drives are used in all industries to precisely control the speed of electric motor driving loads that range from pumps and fans to complex drives on study machines, rolling mill cranes, and similar drives. The most modern method for these drives is the direct torque and stator flux vector control method, which is usually called DTC. This method is realized in an industrial manner by $A B B$ by applying the theoretical background proposed by Blaschke [20], [21] and Depenbrock [22]. This solution is based on both FOC and direct self-control theory. The basic idea of this solution is that motor flux and torque are used as primary control variables, which is contrary to the manner in which traditional AC drives control input frequency and voltage. In principle, however, this solution is similar to what is conducted with a DC drive, where it is achieved in a more straightforward manner.

Wang and Lee [23], [24] stated that by directly controlling motor torque, DTC provides dynamic speed accuracy equivalent to those of closed-loop $\mathrm{AC}$ and DC systems and torque response times are 10 times faster. DTC also does not generate noise such as that produced by conventional PWM AC drives. This work describes a new modular approach to implement the DTC method on a CSI-fed IM drive, which is called the simulation implementation procedure. The dynamic response of the drive is analyzed and presented.

The DTC method is developed from Babaei [25]. The stator voltage and flux equation in the stationary reference frame can be written as follows [11]:

$$
\begin{gathered}
v_{s}=R_{s} i_{s}+\frac{d \lambda_{s}}{d t} \\
\lambda_{s}=\int\left(v_{s}-R_{s} i_{s}\right) d t=\lambda_{\alpha s}+j \lambda_{\beta s} \\
\left|\lambda_{s}\right|=\sqrt{\lambda_{\alpha s}^{2}+\lambda_{\beta s}^{2}}
\end{gathered}
$$

$$
\angle \varphi_{s}=\tan ^{-1}\left(\frac{\lambda_{\beta s}}{\lambda_{\alpha s}}\right)
$$

where $R_{s}$ is the stator resistance, and $\lambda_{s}$ is the stator flux vector in the stationary reference frame. $\left|\lambda_{s}\right|$ and angle $\varphi_{s}$ are the amplitude and position of stator flux vector, respectively.

Determining the stator current reference in the DTC of a CSI-fed IM is desirable so that torque and stator flux can follow their reference values Babaei [25]. The proposed DTC system is based on the stator flux-oriented (SFO) reference frame. This rotating reference frame is written as follows:

$$
\lambda_{q s}=0 \text { and } \lambda_{d s}=\left|\lambda_{s}\right| \angle \varphi_{s}
$$

where $d$ and $q$ are the real and imaginary axes in the SFO reference frame. Therefore, the torque equation is rewritten as follows:

$$
T_{e}=\frac{3}{2}\left(\frac{P}{2}\right) \frac{1}{\omega_{b}}\left(\lambda_{d s} i_{q s}\right)
$$

where $i_{q s}$ is the imaginary part of the stator current vector in the SFO reference frame. Therefore, if $\left|\lambda_{s}{ }^{*}\right|$ and $T_{e}{ }^{*}$ are the stator flux magnitude and torque references, respectively, then the imaginary part of the stator current reference vector that leads to the torque and stator flux magnitude references is as follows:

$$
i_{q s}^{*}=\frac{2}{3}\left(\frac{1}{P}\right) \frac{T_{e}^{*}}{\left|\lambda_{s}^{*}\right|}
$$

Given the existence of a capacitor in the control system and its corresponding losses, the control system will not be sufficiently accurate when Equation (29) is used to control the torque for all rotor speeds.

The proportional-integral (PI) controller output must be limited among proper values to control motor current in all cases, particularly in the starting mode. The output signal of the PI controller is the real part of reference stator current $i_{d s}{ }^{*}$.

Therefore, the stator current reference vector that leads to controlling the IM stator flux and torque is as follows:

$$
\begin{gathered}
i_{s .(d q)^{*}}=i_{d s}{ }^{*}+j i_{q s}{ }^{*} \\
\left|i_{s}{ }^{*}\right|=\sqrt{i_{d s}{ }^{* 2}+i_{q s}{ }^{* 2}}
\end{gathered}
$$

The obtained reference current vector is within the stator flux reference frame. This vector can be generated by the support vector machine of the CSI, when it is transferred to the stationary reference frame. To realize this process, the stator flux position is used to transfer this vector from the stator flux reference frame to the stationary reference frame as follows:

$$
\begin{aligned}
& i_{s .(\alpha \beta)^{*}}=i_{\alpha s}{ }^{*}+j i_{\beta s}{ }^{*}=\left(i_{d s}{ }^{*}+j i_{q s}{ }^{*}\right) e^{j \varphi_{s}} \\
& =\left|i_{s}{ }^{*}\right| \angle\left(\varphi_{s}+\tan ^{-1}\left(\frac{i_{q s}{ }^{*}}{i_{d s}{ }^{*}}\right)\right)
\end{aligned}
$$




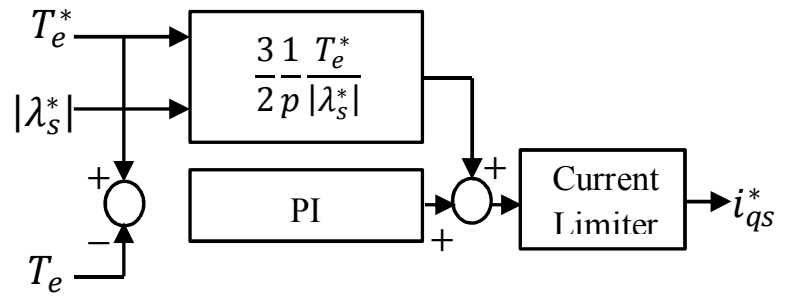

Fig. 8. Reference current calculator for the $q$ axis.

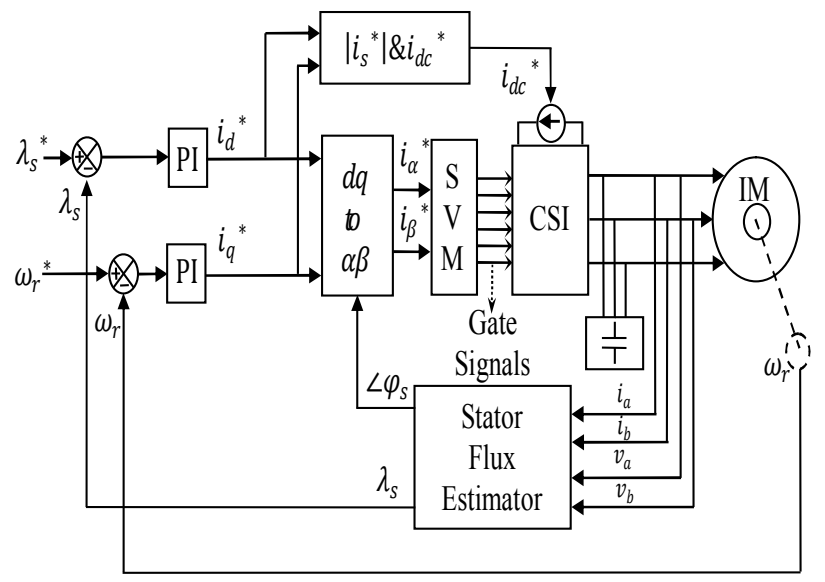

Fig. 9. Block diagram of the proposed DTC.

This reference current vector must be generated first in the CSI and then applied to the motor after removing its harmonics with a filtering capacitor. The current has a nearly sinusoidal waveform that leads to a nearly sinusoidal voltage in motor terminals after feeding the motor and passing through motor impedances.

The speed and stator flux control of an IM with the DTC method is shown in Fig. 9. Separate PI controllers are used to control speed and flux. The input to the speed controller is the error caused by comparing the reference speed and the rotor speed. The output of this controller is the imaginary part of the stator current vector $i_{q s}{ }^{*}$, which is limited to a proper value.

\section{RESULTS AND DISCUSSION}

High-performance, CSI-fed variable speed drives, particularly IM drives, have been managed by using different control methods in recent years. The important methods are vector-based $V / f$ control, IOL control, IFOC, and DTC. Each of these methods has its own unique features. $V / f$ is by far the simplest drive because it requires no parameter knowledge and is essentially an open-loop drive. IOL is a type of nonlinear state feedback control that is completely input-output decoupled at all times even in transients. IFOC provides dynamic torque control performance similar to that of DC motors, and provides fast, near-step changes in machine torque. DTC has simpler control architecture than that of IFOC but with a similar dynamic performance.

The vector-based $V / f$ control method is used to study and verify system performance that is related to the scalar control concept. This method is also useful in real-time control applications. The vector-based $V / f$ control is valid for both steady and transient states. In this paper, IOL control uses an optimal control law that is designed to achieve pre-assigned eigenvalues with minimum possible magnitudes for the feedback gain elements and improved control performance. A new RFO control system in IFOC is implemented for the CSI-fed IM drive, whereas DTC provides simple control architecture with a similar dynamic performance as that of IFOC. A modular Simulink implementation of the IM model is also developed, and the DTC concept is applied to the developed IM model.

Similar studies on vector-controlled inverter-fed drives are mostly discussed with VSIs. Few studies are available on vector-controlled CSIs such as those of Veerachary [15], Salo [19], and Babaei [25]. Cruz [26] also compared IFOC, DTC, and IOL for VSI-fed drives based on steady-state torque ripple, current peak, and switching frequency. $V / f$, IOL, IFOC, and DTC are compared in this paper for CSI-fed IM drives based on the dynamic states of changing speed and torque references in a single simulation cycle. The dynamic performance results of the proposed drives are individually analyzed via sensitivity tests. The results are presented in graphical and tabular forms and verified experimentally to increase understanding.

\section{A. Simulation Results}

The simulation model of the vector-based $V / f$, IOL, IFOC, and DTC control methods for CSI-fed IM drive systems are developed and simulated by using MATLAB simulation software. Based on the simulation results, the dynamic performance results of the developed drives are individually analyzed primarily through sensitivity tests. The results of all drives are compared with one another. The selected tests for the comparison are step changes in the reference speed and torque of the motor drive.

The first test is step change in the reference speed, which is useful when attempting to change from one speed to another. The next test is step change in the reference torque, which is useful in identifying the controller with a high torque response.

Change in speed reference is the first test conducted to compare the motor drives. The results of this test are shown in Figs. 10 to 13. The speed command is varied from 0 to its rated value. The speed response of the IOL drive is faster than those of the other drives and has a settling time of $0.5 \mathrm{~s}$. The DTC and IFOC drives perform similarly but slower than IOL (settling time of less than $1 \mathrm{~s}$ ). The vector-based $V / f$ drive has an inferior speed response compared with the other drives (settling time of more than $1 \mathrm{~s}$ ).

The second test is the torque step test. The results of this test are shown in Figs. 10 to 13. The torque reference is varied from 0 to its rated value. The speed response of the IFOC drive 

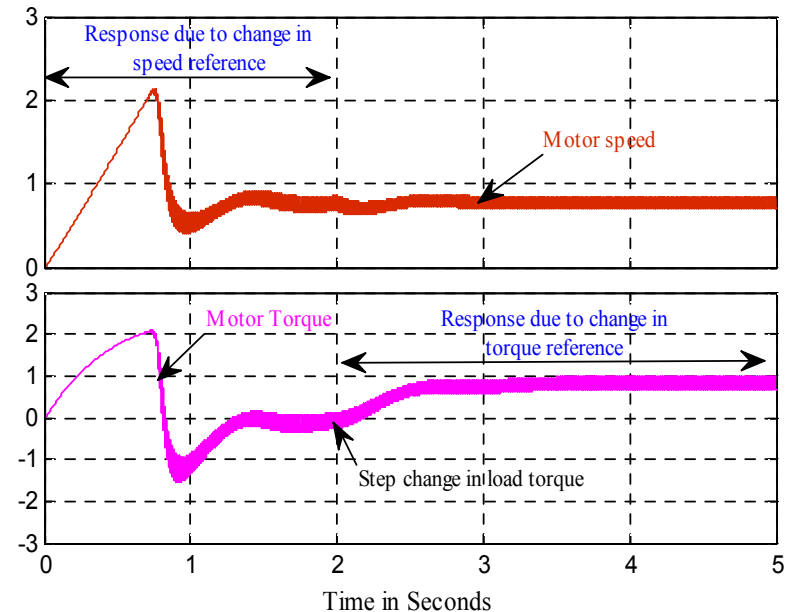

Fig. 10. Speed and torque response of the vector-based $V / f$ control method.
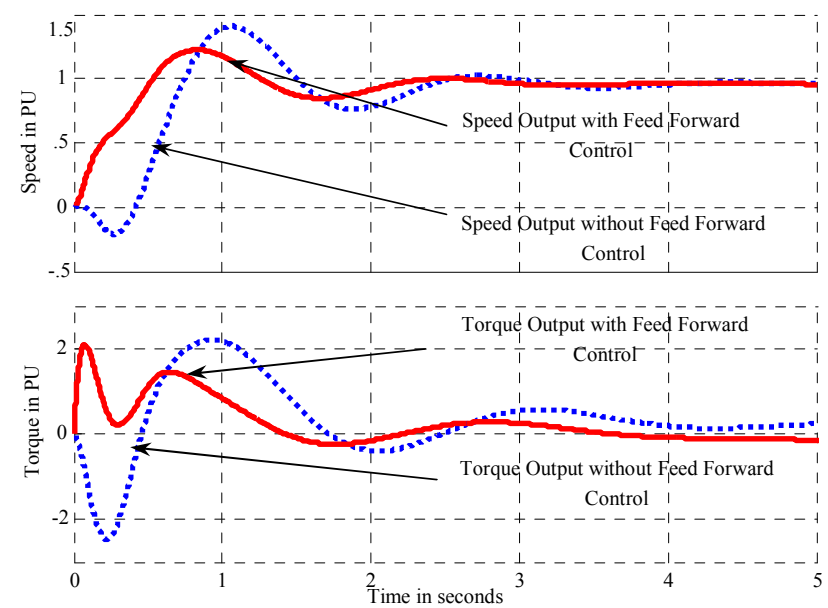

Fig. 11. Speed and torque responses of the IOL control method.
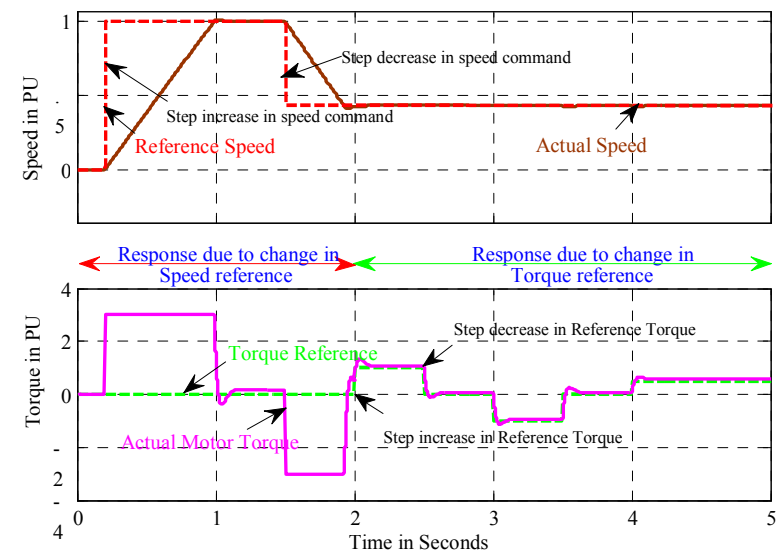

Fig. 12. Speed and torque responses of the IFOC method.

is faster than those of the other drives and has a settling time of $0.2 \mathrm{~s}$. The IOL and DTC drives perform similarly (settling time of less than $0.5 \mathrm{~s}$ ). The vector-based $V / f$ drive has an inferior speed response compared with the other drives (settling time
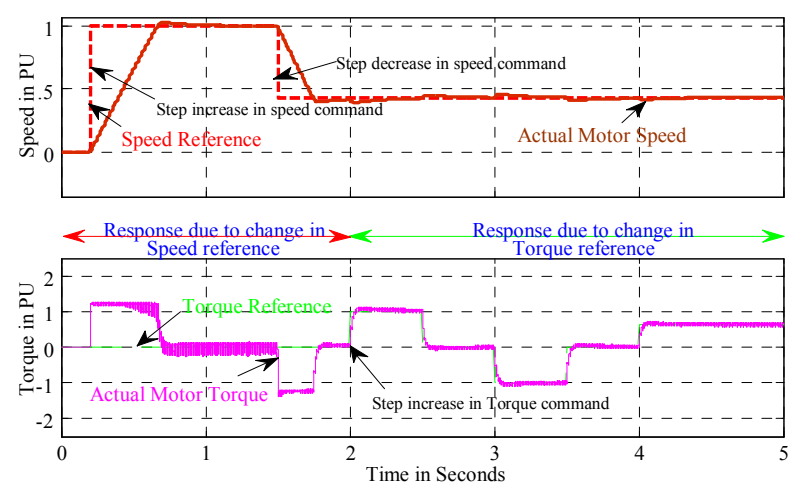

Fig. 13. Speed and torque responses of the DTC method.

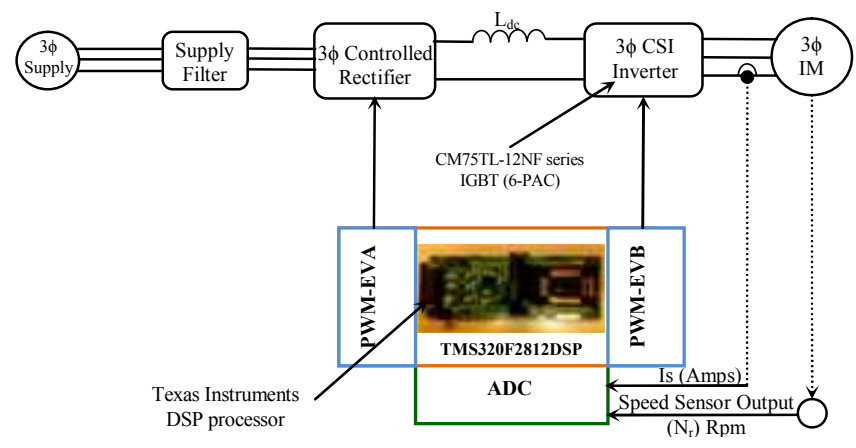

Fig. 14. Schematic of the hardware setup of the CSI-fed IM.

TABLE II

PROTOTYPE MOTOR PARAMETERS

\begin{tabular}{|c|c|c|c|}
\hline \multicolumn{4}{|c|}{$1 \mathrm{Hp}, 3$ phases, Star connected, 4 poles, $415 \mathrm{~V}, 1.8 \mathrm{~A}, 50 \mathrm{~Hz}$} \\
\hline Stator resistance & $=0.087 \Omega$ & $\begin{array}{c}\text { Stator and rotor } \\
\text { leakage reactance }\end{array}$ & $=0.8 \mathrm{e}^{-3} \mathrm{H}$ \\
\hline Rotor resistance & $=0.228 \Omega$ & $\begin{array}{c}\text { Magnetizing } \\
\text { reactance }\end{array}$ & $=34.7 \mathrm{e}^{-3} \mathrm{H}$ \\
\hline
\end{tabular}

of more than $1 \mathrm{~s}$ ).

The motor torque response of the DTC drive during this test is nearly instantaneous within $0.2 \mathrm{~s}$, and is followed closely by the IFOC drive. The IOL and vector-based $V / f$ drives have slower torque responses than the other drives.

\section{B. Experimental Results}

Brief experimental results are presented for the IOL control, IFOC, and DTC methods by using a hardware setup based on TMS320F2812 digital signal processor (DSP) from Texas Instruments Inc. (Texas, USA). The hardware schematic of the laboratory prototype for the CSI-fed IM drive is shown in Fig. 14. The IM ratings are provided in Table II. The inverter consists of CM75TL-12NF. The gate-driving signal is developed by using TMS320F2812 DSP. The software used to develop programs for the TMS320F2812 DSP is provided by Code Composer Studio and MATLAB/Simulink. The processor contains the program downloaded from the computer. 


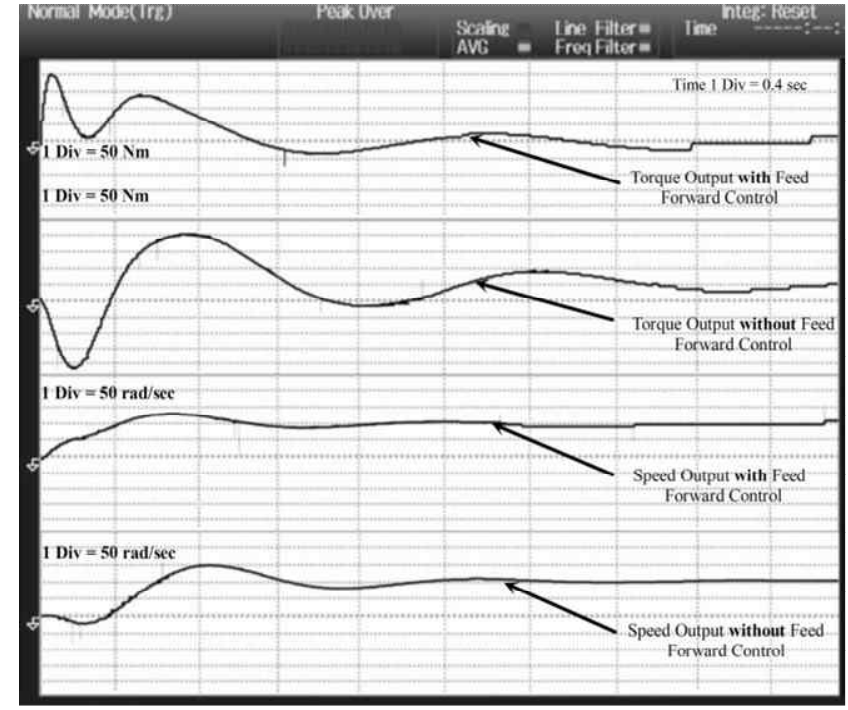

Fig. 15. Experiment result of the torque and speed responses of the IOL control method.

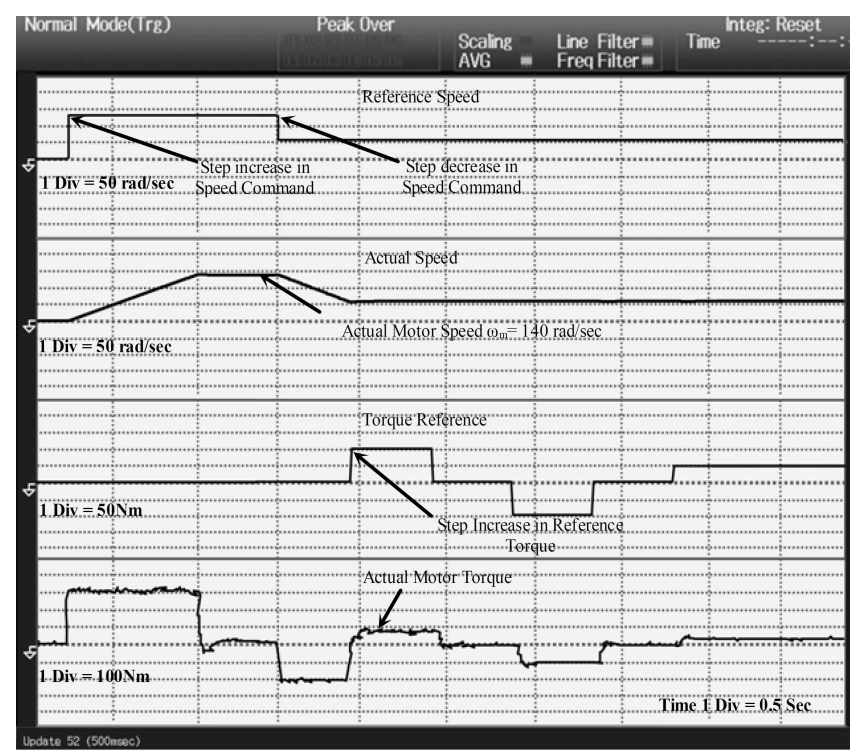

Fig. 16. Experiment result of the torque and speed responses of the IFOC control method.

The experiment result for the IOL method of the vector control technique (Fig. 15) shows the faster settling time with the feedforward control compared with the conventional feedback technique. Thus, the proposed feedforward technique exhibits the best speed response with respect to changes in speed reference and provides smooth and fast settling under speed changes. This result is also verified by determining its dynamic behavior with respect to speed and torque changes, which is presented in table form in the next section.

The IFOC drive also exhibits the best speed response with respect to changes in torque reference as shown in Fig. 16. Similarly, the DTC technique (Fig. 17) depicts a larger torque response within $0.2 \mathrm{~s}$ compared with the other vector control

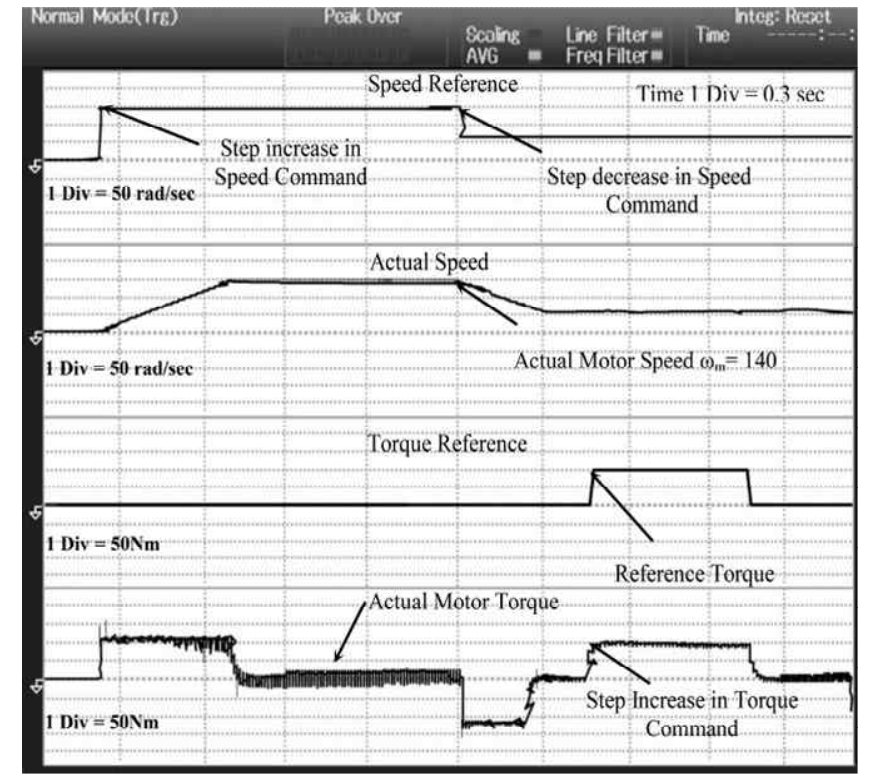

Fig. 17. Experiment result of the torque and speed responses of the DTC control method

TABLE III

Dynamic Performance Results: Step Change in Speed REFERENCE

\begin{tabular}{|c|c|c|c|c|}
\hline \multicolumn{6}{|c|}{ Step change in speed command from 0 to rated speed } \\
\hline \multicolumn{5}{|c|}{ Motor speed response } \\
\hline Performance parameters & $V / f$ & IOL & IFOC & DTC \\
\hline Settling time $\left(t_{s}\right)$ in ms & 1032 & $\mathbf{5 7 0}$ & 976 & 800 \\
\hline Rising time $\left(t_{r}\right)$ in ms & 114 & $\mathbf{8 1}$ & 467 & 315 \\
\hline $\begin{array}{c}\text { Maximum peak overshoot } \\
\left(M_{p}\right) \text { in \% }\end{array}$ & 152 & $\mathbf{2 8}$ & 136 & 139 \\
\hline \multicolumn{6}{|c|}{ Motor torque response } \\
\hline Performance parameters & $V / f$ & IOL & IFOC & DTC \\
\hline Settling time $\left(t_{s}\right)$ in ms & 1031 & 987 & 957 & $\mathbf{5 2 0}$ \\
\hline Rising time $\left(t_{r}\right)$ in ms & 619 & 85 & 79 & $\mathbf{2 7}$ \\
\hline $\begin{array}{c}\text { Maximum peak overshoot } \\
\left(M_{p}\right) \text { in \% }\end{array}$ & 210 & 172 & 293 & $\mathbf{1 5 3}$ \\
\hline
\end{tabular}

techniques when subjected to changes in both speed and torque commands. Thus, DTC is the most efficient torque control technique for an industrial drive in any of the reference changes.

This experimental verification clearly shows that IOL is adaptive for speed response when subjected to changes in speed command. IFOC is also adaptive for speed response when subjected to changes in torque command. DTC is suitable for torque response when subjected to changes in both speed and torque commands.

\section{Tabulated Results}

Table III shows the dynamic speed and torque performance of all four drives with respect to changes in speed reference.

Table IV shows the dynamic speed and torque performance of all four drives with respect to changes in torque reference. The IFOC drive evidently exhibits the best speed response, 
TABLE IV

Dynamic Performance Results: Step Change in Torque REFERENCE

\begin{tabular}{|c|c|c|c|c|}
\hline \multicolumn{5}{|c|}{ Step change in torque command from 0 to full load } \\
\hline \multicolumn{5}{|c|}{ Motor speed response } \\
\hline Performance parameters & $V / f$ & IOL & IFOC & DTC \\
\hline Settling time $\left(t_{s}\right)$ in $\mathrm{ms}$ & 1123 & 417 & 262 & 493 \\
\hline Rising time $\left(t_{r}\right)$ in $\mathrm{ms}$ & 46 & 3 & 118 & 270 \\
\hline $\begin{array}{l}\text { Maximum peak overshoot } \\
\qquad\left(M_{p}\right) \text { in } \%\end{array}$ & 137 & 4 & 3 & 7 \\
\hline \multicolumn{5}{|c|}{ Motor torque response } \\
\hline Performance parameters & $V / f$ & IOL & IFOC & DTC \\
\hline Settling time $\left(t_{s}\right)$ in $\mathrm{ms}$ & 1225 & 889 & 209 & 134 \\
\hline Rising time $\left(t_{r}\right)$ in $\mathrm{ms}$ & 396 & 78 & 58 & 38 \\
\hline $\begin{array}{l}\text { Maximum peak overshoot } \\
\qquad\left(M_{p}\right) \text { in } \%\end{array}$ & 147 & 79 & 140 & 104 \\
\hline
\end{tabular}

followed by the IOL and DTC drives. The DTC drive also exhibits the best instantaneous torque response, followed closely by the IFOC drive. The IOL and vector-based $V / f$ drives are slightly inferior to the others.

The IOL drive evidently exhibits the best speed response, followed by the DTC and IFOC drives. The DTC drive also presents the best instantaneous torque response, followed by the IFOC and IOL. The vector-based $V / f$ is slightly inferior to the others.

\section{CONCLUSIONS}

The results show that the DTC drive is the top performer for a wide range of torque control applications (load-varying applications) with respect to changes in speed and torque references. The IOL drive is the best performer for speed control applications with respect to changes in speed reference, whereas the IFOC drive is the best performer for speed control applications with respect to changes in torque reference. Thus, the DTC method is the most efficient technique for industrial drives with torque control applications to achieve the desired operation of the drive in handling a particular load. IOL is the most efficient method with respect to changes in speed reference for speed control applications, whereas IFOC is the most efficient method with respect to changes in torque reference.

\section{REFERENCES}

[1] K. P. Phillips, "Current-source converter for AC motor drives," IEEE Trans. Ind. Appl., Vol. IA-8, No.6, pp.679-683, Nov 1972.

[2] T. A. Lipo and E. P. Cornell, "State-variable steady-state analysis of a controlled current induction motor drive," IEEE Trans. Ind. Appl., Vol. IA-11, No. 6, pp.704-712, Nov. 1975.

[3] R. Palaniappan, J. Vithayathil, and S. K. Datta, "Principle of a dual current converter for AC motor drives," IEEE Trans. Ind. Appl., Vol. IA-15, No. 4, pp. 445-452, Jul. 1979.

[4] H. S Jung, J. M. Kim, C. U. Kim, C. Choi, and T. U. Jung, "Diminution of current measurement error in vector controlled AC motor drives," Journal Power Electronics, Vol. 5, No. 2, pp. 151-159, Apr. 2005.

[5] R. Krishnan, J. F. Lindsay, and V. R. Stefanovic, "Design of angle-controlled current source inverter-fed induction motor drive," IEEE Trans, Ind. Appl., Vol. IA-19, No. 3, pp.370-378, May 1983.

[6] M. P. Kazmierkowski and H. J. Kopcke, "A simple Control System for Current Source Inverter-Fed Induction Motor Drives," IEEE Trans, Ind. Appl, Vol. IA-21, No. 4, pp. 617-623, May 1985.

[7] N. H. Kim, "Rotor fault detection system for inverter driven induction motors using currents signals and an encoder," Journal Power Electronics, Vol. 7, No. 4, pp. 271-277, Oct. 2007.

[8] D. G. Holmes, B. P. McGrath, and S. G. Parker, "Current regulation strategies for vector-controlled induction motor drives," IEEE Trans. Ind. Electron., Vol. 59, No. 10, pp. 3680-3689, Oct. 2012.

[9] G. Ledwich, "Current source inverter modulation," IEEE Trans. Power Electron., Vol. 6, No. 4, pp.618-623, Oct 1991.

[10] R. Krishnan, Electric Motor Drives Modeling, Analysis, and Control, Prentice Hall of India, 2002.

[11] P. C. Krause and C. H. Thomas, "Simulation of symmetrical induction machinery," IEEE Trans. Power App. Syst. Vol. PAS-84, No. 11, pp.1038-1053, Nov. 1965.

[12] B. K. Bose, Power Electronics and Motor Drives: Advances and Trends, Academic Press, 2006.

[13] B. Wu, S. B. Dewan, and G. R. Slemon, "Eigenvalue sensitivity analysis of GTO-CSI induction machine drives," IEEE Trans. Ind. Appl., Vol. 30, No. 3, pp. 767-775, May/Jun. 1994.

[14] W. H. Wonham, "On pole assignment technique in multi-input controllable linear systems," IEEE Trans. Autom. Control, Vol. AC-12, No. 6, pp. 660-665, Dec. 1967.

[15] M. Veerachary, "Optimal control strategy for a current source inverter fed induction motor," Elsevier: Computers and Electrical Engineering, Vol. 28, No. 4, pp. 255-267, Jul. 2002.

[16] H. W. Smith and E. J. Davison, "Design of industrial regulators integral feedback and feed forward control," in PROC. IEEE, Vol. 19, No. 8, pp. 1210-1216, Aug. 1972.

[17] P. C. Krause, O. Wasynczuk, and S. D. Sudhoff, Analysis of Electric Machines and Drive Systems, Wiley-IEEE Press, 2002.

[18] P. Vas, Electrical Machines and Drives, Oxford University Press, 1992.

[19] M. Salo and H. Tuusa, "Vector-controlled PWM current source-inverter-fed induction motor drive with a new stator current control method," IEEE Trans. Ind. Electron., Vol. 52, No. 2, pp. 523-531, Apr. 2005.

[20] F. Blaschke, "A new method for the structural decoupling of A.C. induction machines," in Conf. Rec. IFAC, Duesseldorf, pp. 1-15, 1971.

[21] F. Blaschke, "The principle of field-orientation as applied to the transvector closed-loop control system for rotating-field machines," Siemens Rev., Vol. 34, pp. 217-220, 1972.

[22] M. Depenbrock, "Direct self-control (DSC) of inverter-fed induction machine," IEEE Trans. Power Electron, Vol. 3, No. 4, pp. 420-429, Oct. 1988.

[23] W. Wang, M. Cheng, Z. Wang, and B. Zhang, "Fast switching direct torque control using a single dc-link current sensor," Journal of Power Electronics, Vol. 12, No. 6, pp. 895-903, Nov. 2012.

[24] D. H. Lee, T. H. Kim, and J. W. Ahn, “A hydraulic-oil pump 
system using SR drive with a direct torque control scheme," Journal of Power Electronics, Vol. 9, No. 3, pp. 491-498, May 2009.

[25] M. Babaei, and H. Heydari, Direct Torque Control of Pulse Width Modulation Current Source Inverter-fed Induction Motor by Novel Switching Method, Taylor \& Francis: Electric Power Components and Systems, pp. 38:514-532, 2010.

[26] C. Cruz, M. A. Gallegos, R. Alvarez, and F. Pazos, "Comparison of several nonlinear controllers for induction motors," IEEE International Power Electronics Conference-CIEP, pp. 134-139, 2004.

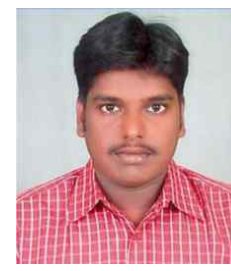

Arul Prasanna Mark was born on May 18, 1985. He received his B.E. in Electrical and Electronics Engineering in 2006 and M.E. in Power Electronics and Drives in 2008 from Anna University, Chennai, Tamil Nadu, India. $\mathrm{He}$ is currently pursuing his Ph.D. in Power Electronics and Drives at Anna University, Chennai, Tamil Nadu, India. His research interests include power electronics and drives, current source inverters, and AC drives and their applications. He is currently an assistant professor at the Department of Electrical and Electronics Engineering at the PSNA College of Engineering and Technology, Dindigul, Tamil Nadu, India.

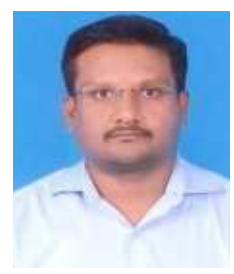

Gerald Christopher Raj Irudayaraj was born on January 7, 1977. He received his B.E. in Electrical and Electronics Engineering from Madurai Kamaraj University, Madurai, Tamil Nadu, India in 1999 and his M.E. and Ph.D. in Power Electronics and Drives from Anna University, Chennai, Tamil Nadu, India in 2006 and 2013, respectively. He is presently an associate professor at the Department of Electrical and Electronics Engineering, PSNA College of Engineering and Technology, Dindigul, Tamil Nadu, India. His current research interests include power electronics and drives, current source inverters, and $\mathrm{AC}$ drives and their applications.

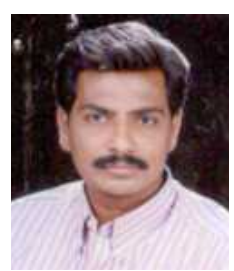

Rajasekaran Vairamani was born in Madurai, Tamil Nadu, India in 1971. He received his B.E. in Electrical and Electronics Engineering, M.E. in Power Systems, and Ph.D. from Madurai Kamaraj University, Madurai, Tamil Nadu, India in 1994, 1997, and 2007, respectively. $\mathrm{He}$ presently heads the Electrical and Electronics Department, PSNA College of Engineering and Technology, Dindigul, Tamil Nadu, India. He is a certified energy auditor. His current research interests include power systems, energy, power quality, and power electronics energy.

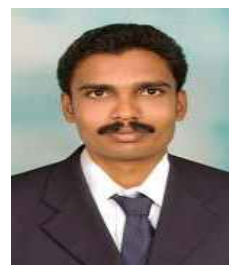

Kaliamoorthy Mylsamy received his B.E. in Electrical and Electronics Engineering at Madras University, Chennai, India in 1999 and his M.Tech in Electrical Drives and Control from Pondicherry University, Puducherry, India in 2006. He was a gold medalist for the academic years 2004 to 2006 . $\mathrm{He}$ has a decade of teaching experience for electrical and electronics engineering undergraduate and postgraduate students. He is presently an associate professor of electrical and electronics engineering at PSNA College of Engineering and Technology, Dindigul, Tamil Nadu, India. His current research interests include alternative energy sources, fuel cells, energy conversion, multi-level inverters, analysis and control of power electronics devices, power quality, and active harmonic analysis. Visit www.kaliasgoldmedal.yolasite.com. 